\title{
Diurnal Variation in Thigmotropic Inhibition of Stem Elongation
}

\author{
Tami Van Gaal and \\ John E. Erwin ${ }^{1}$
}

AdDitionAl INDEX wORDs. circadian rhythm, thigmotropism, wind, tomato, cosmos

\begin{abstract}
SUMMARY. Wind, touching, and/or mechanical stress can restrict stem elongation. Removal of the registration of the growth retardant daminozide for use on edible crops increased interest in thigmotropic inhibition of stem elongation to control plant height in greenhouse crops, as well as a general desire by growers to decrease chemical inputs for floriculture crops. Since stem elongation varies diurnally, the question arises as to whether wind inhibition of stem elongation varies over a 24 -hour period. Tomato (Lycopersicon esculentum) 'MoneyMaker' and cosmos (Cosmos bipinnatus) 'Imperial Pink' seedlings were placed under each of 10 wind perturbation treatments [applied for different durations and at different times during a 24-hour period; wind speed (perpendicular to the media) at seedling level was $30 \mathrm{~km} \cdot \mathrm{h}^{-1}(18.6$ $\mathrm{mph}$ )] for 30 days. Data were collected on plant height and leaf number on days 1 and 30 . The effect of wind on stem elongation differed with species; wind treatments restricted stem elongation more on cosmos than tomato $(\mathbf{5 3} \%$ and $\mathbf{2 0} \%$, respectively, across treatments). Tomato elongation was most restricted when seedlings received wind all day, all night, or all day and night. Within short-term treatments, internode length was least when tomato seedlings received a mid-day wind treatment. Cosmos elongation was most restricted when seedlings received a wind treatment all day or all night. Within shortterm treatments, cosmos internode elongation was most restricted with early- and mid-day wind treatments. Data here suggest wind effects on elongation vary diurnally. In addi-
\end{abstract} tion, the magnitude of wind effects on 
elongation varied with species and was greatest during the beginning of the day on cosmos, which mirrors when stem elongation is most sensitive to temperature fluctuations.

W Ind, touching, or mechanical stressreducesstem elongation in many plants (Biddington, 1986; Jaffe and Forbes, 1993; Telewski and Jaffe, 1986). Effects of mechanical stress (including wind) and/or touching on plant morphogenesis are referred to as thigmotropism (Jaffe, 1973). Reduction in stem elongation resulting from thigmotropism is associated with a stimulation of ethylene biosynthesis (Biro and Jaffe, 1984) and a reduction in gibberellin biosynthesis. Ethylene reduces stem elongation primarily by changing the direction of cell wall cellulose fibril deposition, resulting in increased radial expansion or internode thickening (Ridge, 1973; Takano et al., 1995) at the expense of cell elongation. Mechanical stress reduced gibberellin biosynthesis in bean plants that resulted in decreased stem elongation; gibberellins ( primarily $\mathrm{GA}_{1}$ ) stimulate cell elongation and division (Takano et al., 1995).

Removal of the registration of the growth retardant daminozide (B-Nine; Uniroyal Chemical Co., Greenville, S.C.) for use on edible crops increased interest in thigmotropic inhibition of stem elongation to control plant height in greenhouse crops, as well as, a general desire by growers to decrease chemical inputs for floriculture crops (Latimer, 1991; Latimer and Thomas, 1991; Marshal, 1991). Brushing seedlings reduces stem elongation on many vegetable crops (Alder and Wilcox, 1987; Jaffe et al., 1984; Latimer, 1991; Latimer and Thomas, 1991) and offers a nonchemical method for height control. Historically, brushing jerusalem cherry [Solanum psendocapsicum (a potted floriculture crop)] was a common height control method $(\mathrm{N}$. Anderson, personal communication) in greenhouse production. Garner and Bjorkman (1996) showed that 10 to 40 brush strokes/d resulted in a $20 \%$ reduction in tomato stem elongation with little additional inhibition when more than 10 brush strokes/d was applied. Intervals between strokes as long as 10 min resulted in the same reduction as the same daily dose applied once.
Temperature management is also used to control stem elongation in greenhouse crops. Stem elongation rate varies diurnally (Erwin and Heins, 1995; Erwin et al., 1992; Tutty et al., 1994; Went, 1957). Stem elongation typically decreases during the photoperiod and increases during the scotoperiod (Erwin, 1992; Erwin and Heins, 1995; Erwin et al., 1989a; Shimizu and Heins, 2000; Tutty et al., 1994; Went, 1957). Therefore, the greatest stem elongation rate usually occurs at the end of the scotoperiod and beginning of the photoperiod. Greenhouse growers routinely use temperature manipulation to manage stem elongation of floriculture crops (Erwin et al., 1989a, 1989b) and vegetable crops (Erwin et al., 1992); growers decrease temperatures at the end of the scotoperiod and the beginning of the photoperiod to inhibit elongation when it is greatest (Erwin et al., 1989a).

Diurnal variation in the effects of mechanical stress on stem elongation has been reported. Inhibition of stem elongation via brushing varies diurnally and is greatest when applied at the end of the scotoperiod and beginning of the photoperiod (Anderson-Bernadas et al., 1997). In contrast, Garner and Bjorkman (1996) suggested no difference in inhibition of tomato stem elongation by brushing in the morning versus afternoon. The question arises as to whether wind inhibition of stem elongation varies diurnally. Wind treatments are preferable to brushing as no physical contact occurs and leaves are not scratched. We hypothesize wind inhibition of stem elongation varies diurnally and is greatest when applied at the end of scotoperiod and beginning of photoperiod. We also wanted to determine whether species differ in inhibition of stem elongation resulting from wind.

\section{Materials and methods}

'MoneyMaker' tomato and 'Imperial Pink' cosmos seeds were sown in a soilless medium (50\% sphagnum peat, $25 \%$ perlite, and $25 \%$ vermiculite by volume) (Baccto Grow Mix; Michigan Peat Co., Houston, ) on 17 and 19 Oct. and were placed in a glass-glazed greenhouse maintained at $25 \pm 2{ }^{\circ} \mathrm{C}$ $\left(77.0 \pm 3.6^{\circ} \mathrm{F}\right)$ under intermittent mist (15 s every $15 \mathrm{~min}$ ). Germination required 4 and $8 \mathrm{~d}$ for cosmos and tomato, respectively. Germinated seedlings were selected for uniformity based on germination time and size, and were transplanted into $254-\mathrm{cm}^{3}$ $\left(15.5\right.$ inch $\left.^{3}\right)$ plastic pots $[10.2-\mathrm{cm}$ (4 inches) diameter] containing the same soilless medium when cotyledons were horizontal to the media surface. Two days after transplant, 10 potted seedlings of each species were placed in plastic carrier trays and were placed under each of the wind perturbation treatment environments in a constant $18 \pm 2{ }^{\circ} \mathrm{C}\left(64.4 \pm 3.6^{\circ} \mathrm{F}\right)$ greenhouse (Table 1) on 14 and 29 Nov. under ambient light conditions (St. Paul, Minn.) plus $50 \mu \mathrm{mol} \cdot \mathrm{m}^{-2} \cdot \mathrm{s}^{-1}$ supplemental lighting provided with high pressure sodium lamps. An opaque cloth was pulled over plants and fans from 1700 to $0800 \mathrm{HR}$ daily to minimize light pollution from adjoining greenhouses (9-h photoperiod). Note "all day" and "all night" wind treatments differed 6 $\mathrm{h}$ in length (Table 1 ).

Wind treatments were applied using a $50.8-\mathrm{cm}$ (20-inch) fan blade, (model \#4C510B; Dayton Electric Mfg. Co., Chicago) suspended 70 $\mathrm{cm}$ (27.6 inches) above seedlings. Fan control was accomplished using digital timers (Intermac, Chicago). Wind speed at seedling level was $30 \mathrm{~km} \cdot \mathrm{h}^{-1}$ as determined using an anemometer. Fans were positioned perpendicular to the greenhouse bench so wind blew directly down on seedlings. Seedlings were watered as needed (different treatments required different amounts of water) and were fertilized weekly with a solution containing $28.6 \mathrm{~mm}$ nitrogen, $2.8 \mathrm{~mm}$ phosphorus, and $8.5 \mathrm{~mm}$ potassium. Care was taken not to leach pots to insure fertility was similar between treatments.

Data were collected on seedling height and node number when plants were moved into treatment environments. Final plant height and leaf number were collected $30 \mathrm{~d}$ after initiation of treatments. Average internode length was calculated for each seedling by dividing the change in plant height by the change in node number. The experiment was organized in a completely randomized statistical design in a factorial arrangement and was replicated twice over time. There were 10 seedlings per replicate. Analysis of variance was employed to determine treatment and species effects and potential interactions. Statistical significance $(P \leq 0.05)$ among treatment means was determined using the Fisher's 
Table 1. Effect of wind perturbation time and duration on 'Money Maker' tomato and 'Imperial Pink' cosmos internode length. Plants received a wind treatment applied perpendicular to seedlings using a $50.8-\mathrm{cm}(20$ inches) fan blade suspended $70 \mathrm{~cm}$ (27.6 inches) above seedlings. Wind speed at seedling level was $30 \mathrm{~km} \cdot \mathrm{h}^{-1}(18.6 \mathrm{mph})$. Internode length was calculated by dividing change in height by the change in node number for each plant. Note all day and all night treatments differed in treatments length $(9 \mathrm{vs} .15 \mathrm{~h})$. Analysis of variance was conducted to distinguish treatment and species effects on average internode length.

\begin{tabular}{|c|c|c|c|c|c|}
\hline \multirow{2}{*}{\multicolumn{2}{|c|}{$\begin{array}{l}\text { Wind } \\
\text { treatment time }\end{array}$}} & \multicolumn{4}{|c|}{ Avg internode length $(\mathrm{cm})^{\mathrm{z}}$} \\
\hline & & \multirow{2}{*}{$\begin{array}{c}\text { Tomato } \\
2.7 b^{x}\end{array}$} & \multirow{2}{*}{$\begin{array}{c}\text { Relative to } \\
\text { no wind }\end{array}$} & \multirow{2}{*}{$\frac{\text { Cosmos }}{5.0 \mathrm{e}}$} & $\begin{array}{c}\text { Relative to } \\
\text { no wind }\end{array}$ \\
\hline No wind & & & & & $0.0 \mathrm{e}$ \\
\hline All day and night $(0000-2400 \mathrm{H}$ & HR) & $2.2 \mathrm{a}$ & $-0.5 \mathrm{a}$ & $2.4 \mathrm{a}$ & $-2.6 \mathrm{a}$ \\
\hline All day $(0805-1705$ HR $)$ & & $2.4 \mathrm{a}$ & $-0.3 \mathrm{a}$ & $3.3 \mathrm{~b}$ & $-1.7 \mathrm{~b}$ \\
\hline All night (1700-0805 HR) & & $2.3 \mathrm{a}$ & $-0.4 \mathrm{a}$ & $2.7 \mathrm{ab}$ & $-2.3 \mathrm{ab}$ \\
\hline Early-day (0805-0810 HR) & & $2.7 \mathrm{~b}$ & $-0.0 \mathrm{~b}$ & $3.7 \mathrm{~b}$ & $-1.3 \mathrm{bc}$ \\
\hline Mid-day (1230-1235 HR) & & $2.6 \mathrm{ab}$ & $-0.1 \mathrm{ab}$ & $3.7 \mathrm{bc}$ & $-1.3 \mathrm{bc}$ \\
\hline Late-day (1650-1655 HR) & & $2.7 \mathrm{~b}$ & $-0.0 \mathrm{~b}$ & $3.9 \mathrm{c}$ & $-1.1 \mathrm{~b}$ \\
\hline Early-night (1705-1710 HR) & & $2.8 \mathrm{~b}$ & $+0.1 \mathrm{~b}$ & $4.6 \mathrm{de}$ & $-0.4 \mathrm{de}$ \\
\hline Mid-night (0030-0035 HR) & & $2.8 \mathrm{~b}$ & $+0.1 \mathrm{~b}$ & $4.3 \mathrm{~cd}$ & $-0.7 \mathrm{~cd}$ \\
\hline Late-night (0755-0800 HR) & & $3.3 \mathrm{~b}$ & $+0.6 \mathrm{~b}$ & $4.3 \mathrm{~cd}$ & $-0.7 \mathrm{~cd}$ \\
\hline Across wind treatments & & 2.7 (a) & & $3.8(\mathrm{~b})$ & \\
\hline Species & $* * *$ & & & & \\
\hline Wind treatment & *** & & & & \\
\hline Species $\times$ wind & $* * *$ & & & & \\
\hline
\end{tabular}

${ }^{2} 1.0 \mathrm{~cm}=0.39$ inch.

"Relative to no wind" refers to the difference between the treatment mean and untreated plants (treatment mean - untreated) within a species.

${ }^{x}$ Letters denote mean comparisons across treatments using Fisher's least significant difference within a species. ${ }^{* *}$ Significant at $P \leq 0.001$.

protected least significant difference procedure for mean separation.

\section{Results and discussion}

Inherent stem elongation and the effect of wind treatments on that elongation differed between species (Table 1). Tomato internode length was less than that for cosmos [2.7 and $3.8 \mathrm{~cm}$ (1.06 and 1.50 inches), respectively] across wind treatments (Table 1). Additionally, tomato stem elongation was less affected by wind treatments than cosmos (Table 1). Tomato internode length was 2.7 and $2.2 \mathrm{~cm}$ [ 1.06 and 0.87 inches ( $19 \%$ reduction)] for untreated seedlings vs. seedlings receiving an all day and night wind treatment, respectively (Table 1 ). A $19 \%$ reduction on tomato stem elongation by wind treatment is consistent with the reduction in stem elongation observed after tomato plants were brushed 10 times /d observed by Garner and Bjorkman (1996). In contrast to tomato, cosmos internode length was reduced from 5.0 to $2.4 \mathrm{~cm}$ [ 1.97 to 0.94 inches $(52 \%$ reduction $)$ ] on untreated seedlings versus seedlings that received a wind treatment all day and night, respectively (Table 1 ).
Restriction of stem elongation was greatest when either tomato or cosmos received a wind treatment all day and night (Table 1). However, species differed in responses to shorter term wind treatments. With tomato, all day, all night, and all day and night wind treatments reduced internode length compared to untreated plants (Table 1). Percent inhibition of stem elongation did not vary between the all day and the all night treatments which agree with results of Garner and Bjorkman (1996) with brushing treatments on tomato. In contrast to tomato, all treatments except for the early-night treatment reduced cosmos internode length compared to untreated seedlings. Seedlings that received a wind treatment all day and night or all night only had the shortest internodes (Table 1). Cosmos seedlings that received the early- and mid-day wind treatments showed as much restriction of internode elongation as seedlings that received a wind treatment all day or all night (Table 1 ).

It is not surprising variation in sensitivity of stem elongation to wind varies between species as sensitivity of stem elongation to temperature manipulation also varies between vegetable species (Erwin et al., 1992). In addition to species variation to thigmotropic inhibition of stem elongation, ecotypes within a species [e.g., chickweed (Stellaria longipes)] can vary in stem elongation responses to wind (Emery et al., 1994).

The differential response of cosmos to wind treatments over a 24-h period mimicked circadian variation in other thigmotropic and temperature restriction of stem elongation responses reported. For instance, variation in cosmos seedling stem elongation to wind over a 24 -h period was similar to variation in the effect of mechanical stress on bean (Phaseolusvulgaris) stem elongation where elongation was most restricted by mechanical stress applied at the end of the night and the beginning of the day (Anderson-Bernadas et al., 1997). Similarly, restriction of stem elongation by cool temperatures is greatest at the end of the night and the beginning of the day (Erwin et al., 1989a). It is interesting that tomato stem elongation was not greatly affected by early morning treatments. Clearly, additional testing of additional species will need to be conducted to determine whether the lack of response of tomato to early day wind treatments is an anomaly or something exhibited by other species as well.

Leaf number did not differ among wind treatments (data not shown). Leaf unfolding rate is primarily a function of average daily temperature (Karlsson et al., 1989). It is possible that wind treatments could result in differences in leaf temperature between plants if there were differences in transpiration rate between treatments resulting from the wind treatments. Plant temperature data were not collected here but likely did not differ significantly between treatments since leaf number did not vary between treatments as would be expected if plant temperatures differed. It must also be noted that seedlings were not damaged in any way by wind treatments, leaf necrosis etc.

Data presented here may provide some rationale for variation in effectiveness of similar thigmotropic treatments on stem restriction reported in experiments by different research groups. A lack of a stem elongation response to a thigmotropic treatment may be due, in part, to the time of day or night that the treatment was applied if a species, such as cosmos, is differentially sensi- 
tive to thigmotropic treatments during a 24-h period.

\section{Conclusion}

Taken together, short-term wind restriction of stem elongation on cosmos paralleled effects of short-term temperature drops effects on stem elongation where plants were most sensitive to temperature drops or wind during the end of the night and the early part of the day. However, restriction of elongation in tomato appeared to increase with the length of time plants were blown. Data here suggest that if a short-term wind treatment is tried in the industry to restrict stem elongation, the early part of the day would be the best time to apply a short-term treatment. However, there are likely differences in the effectiveness of such treatments between species in limiting elongation as was the case with tomato. As a result, additional experimentation is clearly needed to develop grower recommendations; however, our data show that the impact of wind on stem elongation can vary diurnally.

\section{Literature cited}

Adler, P.R. and G.E. Wilcox. 1987. Influence of thigmic stress or chlormequat chloride on tomato morphology and elemental uptake. J. Plant Nutr. 10:831-840.

Anderson-Bernadas, C., G. Cornelissen, C.M. Turner, and W.L. Koukkari. 1997. Rhythmic nature of thigmomorphogenesis and thermal stress of Phaseolus vulgaris $\mathrm{L}$. shoots. J. Plant Physiol. 151:575-580.

Biddington, N.L. 1986. The effects of mechanically-induced stress in plants-A review. Plant Growth Regulat. 4:103-123.

Biro, R.L. and M.J. Jaffe. 1984. Thigmomorphogenesis: Ethylene evolution and its role in the changes observed in mechanically perturbed bean plants. Physiol. Plant. 62:289-296.
Emery, R.J.N., D.M. Reid, and C.C. Chinnappa. 1994. Phenotypic plasticity of stem elongation in two ecotypes of Stellaria longipes: The role of ethylene and response to wind. Plant Cell Environ. 17:691-700

Erwin, J.E. 1992. Utility of DIF to regulate vegetable transplant stem elongation. HortScience 27:615.

Erwin, J.E., R.D. Heins, R. Berghage, B.J. Kovanda, W.H. Carlson, and J. Biernbaum. 1989a. Cool mornings can control plant height. GrowerTalks 52(9).

Erwin, J.E., R.D. Heins, and M.G. Karlsson. 1989b. Thermomorphogenesis in Lilium longiflorum, Thunb. Amer. J. Bot. 76:47-52.

Erwin, J.E., R.D. Heins, W. Carlson, and S. Newport. 1992. Mini review: Diurnal temperature fluctuations and mechanical manipulation affect plant stem elongation. PGRSA Quarterly 20(1):1-17.

Erwin, J. and R. Heins. 1995. Thermomorphogenic responses in stem and leaf development. HortScience 30:940-949.

Garner, L.C. and T. Bjorkman. 1996. Mechanical conditioning for controlling excessive elongation in tomato transplants: Sensitivity to dose, frequency, and timing of brushing. J. Amer. Soc. Hort. Sci. 121:894-900.

Jaffe, M.J. 1973. Thigmomorphogenesis: The response of plant growth and development to mechanical stimulation. Planta 114:143-157.

Jaffe, M.J. and S. Forbes. 1993. Thigmomorphogenesis: The effect of mechanical perturbation on plants. Plant Growth Regulat. 12:313-324.

Jaffe, M.J., F.W. Telewski, and P.W. Cooke. 1984. Thigmomorphogenesis: On the mechanical properties of mechanically perturbed bean plants. Physiol. Plant. 62:73-78.
Karlsson, M.G., R.D. Heins, J.E. Erwin, R.D. Berghage, W.H. Carlosn, and J.A. Biernbaum. 1989. Temperature and photosynthetic photon flux influence chrysanthemum shoot development and flower initiation under short-day conditions. J. Amer. Soc. Hort. Sci. 114:158-163.

Latimer, J.G. 1991. Brushing can control transplant height. Amer. Veg. Grower 39:98, 102-103.

Latimer, J.G. and P.A. Thomas. 1991. Application of brushing for growth control of tomato transplants in a commercial setting. HortTechnology 1(1):109-110.

Marshall, E. 1991. A is for apple, alar, and ... alarmist? Science 254:20-22.

Ridge, I. 1973. The control of cell shape and rate of cell expansion by ethylene: Effects on microfibril orientation and cell wall extensibility in etiolated peas. Acta Bot. Neerl. 22:144-158.

Shimizu, H. and R.D. Heins. 2000. Photoperiod and the difference between day and night temperature influence stem elongation kinetics in Verbena bonariensis. J. Amer. Soc. Hort. Sci. 125:576-580.

Takano, M., H. Takahashi, and H. Suge. 1995. Mechanical stress and gibberellin: Regulation of hollowing induction in the stem of a bean plant, Phaseolus vulgaris $\mathrm{L}$. Plant Cell Physiol. 36:101-108.

Telewski, F.W. and M.J. Jaffe. 1986. Thigmomorphogenesis: Field and laboratory studies of Abies fraseri in response to wind or mechanical perturbation. Physiol. Plant. 66:211-218.

Tutty, J.R., P.R. Hicklenton, D.N. Kristie, and K.B. McRae. 1994. The influence of photoperiod and temperature on the kinetics of stem elongation in Dendranthema grandiflorum. J. Amer. Soc. Hort. Sci. 119:138-143.

Went, F.W. 1957. The experimental control of plant growth: With special reference to the Earhart Plant Research Laboratory at the California Institute of Technology. Chronica Botanica 17:329-336. 